\title{
Influence of Post-Stroke Depression on Functional Independence in Activities of Daily Living
}

\author{
Charles I Ezema1, Petronella C Akusoba ${ }^{1}$, Martins C Nweke ${ }^{*}$, Chigozie U \\ Uchewoke $^{1}$, Joshua Agono ${ }^{1}$, Godspower Usoro ${ }^{1}$
}

\section{OPEN ACCESS}

Citation: Ezema CI, Akusoba PC, Nweke $\mathrm{MC}$, Uchewoke CU, Agono J, Usoro G. Influence of Post-Stroke Depression on Functional Independence in Activities of Daily Living. Ethiop J Health Sci.2018;29 (1):841.

doi:http://dx.doi.org /10.4314/ejhs.v29i1.5 Received: April 19, 2018

Accepted: May 25, 2018

Published: January 1, 2019

Copyright: (C) 2018 Charles I Ezema et al. This is an open access article distributed under the terms of the Creative Commons Attribution License, which permits unrestricted use, distribution, and reproduction in any medium, provided the original author and source are credited. Funding: Bona District Health Bureau and Abem private clinic.

Competing Interests: The authors declare that this manuscript was approved by all authors in its form and that no competing interest exists.

Affiliation and Correspondence:

${ }^{1}$ Department of Medical Rehabilitation, Faculty of Health Sciences and Technology University of Nigeria Nsukka, Enugu Campus, Enugu Nigeria

*Email: martins.nweke@gmail.com

\section{ABSTRACT}

BACKGROUND: Little attention has been paid to screening of depression among stroke survivors in outpatient physiotherapy clinics. Post-stroke depression is reported to have a negative impact on functional recovery. However, the exact influence on the outcome of rehabilitation such as level of functional independence remains controversial. This study aims at ascertaining the influence of post-stroke depression on functional independence in activities of daily living.

METHODS: The study is a cross sectional survey of stroke survivors attending outpatient physiotherapy clinics of the University of Nigeria Teaching Hospital (UNTH) Enugu, and the Enugu State University Teaching Hospital (ESUTH). Participants were evaluated for socio-demographic characteristics. Post-stroke depression and level of functional recovery in Activities of Daily Living were assessed using the Hamilton Depression Rating Scale and the Barthel Index respectively. Data was analyzed using SPSS version 23, with a set at 0.01 .

RESULTS: A total of 66 participants, 42 females and 24 males, were purposively recruited into the study. Over 80\% (56) of the participant had depression, with over 50\% (32) being severely depressed. Post-stroke depression was associated with less functional independence in activities of daily living ( $p=0.000)$. A significant difference was found in the level of functional independence between participants with and without depression $(p=0.00)$.

CONCLUSION: Participants with post-stroke depression have less independence in activities of daily living. A longitudinal study with a larger sample size is, however, recommended so as to improve the external validity. In the mean time, outpatient rehabilitation of depressed stroke survivors should include pharmacological and psychological components.

KEYWORDS: Stroke, Depression, functional independence, activities of daily living 


\section{INRODUCTION}

Stroke is currently the most common cause of neurological disability and functional dependence in activities of daily living (ADL) in adults (1). Community-based African studies revealed an agestandardized annual stroke incidence rate of up to 316 per 100000 population, and age-standardized prevalence rates of up to 981 per 100000 (2). While mortality rates have been declining since the $1950 \mathrm{~s}$, due in part to advances in acute stroke treatment and early symptom recognition, the prevalence of stroke has relatively remained the same and may even be on the increase (3). About two-thirds of stroke survivors have residual neurological deficits that impair functional abilities in ADL: approximately half are left with disabilities making them dependent on others for most, if not all, ADL (4). The peculiarity of impairment differs from person to person, and varies also with the regions of the central nervous system that have sustained damage (4). Commonest impairments include physical impairments in upper limb use and in functional walking. In any case, the volume of disability associated with stroke is still alarming (5). This volume of impairment in ADL among survivors of stroke is said to be due to factors such as late presentation to clinic, lack of advancement in therapeutic approach and post-stroke depressive symptoms of lack of motivation and requisite cognitive ability and feeling of insecurity $(5,6)$.

Post-stroke Depression (PSD) is a frequent and relevant complication of stroke that negatively interferes with functional outcome $(7,8)$. The mechanism of interference or impact on functional recovery is postulated to be through decreasing motivation and cognitive abilities (9). The postulation is further supported by the fact that relearning and recovering of motor functions after stroke requires most cognitive domains including working memory attention, and executive function (10). Motor learning is slowed when cognitive performance and self-efficacy are impaired: it limits the ability of the stroke survivors to understand, repeat, refine and analyze recovering movement (10). PSD is present in at least 30\% of survivors from stroke. In fact, Robinson and Jorge
(2016) found that PSD is present in approximately $85 \%$ of patients with strokes, and can be developed any time up to 5 years following stroke (6). It has been associated with delayed rehabilitation outcomes (11) as well as social withdrawal after stroke and poor performance in activities of daily living (12).

Although PSD is reported to have a negative impact on functional recovery, its effects on the outcome of rehabilitation such as level of functional independence remains controversial (13). Some studies $(14,15)$ reveal that PSD has a negative impact on recovery of functions of daily life activities, but other studies $(16,17)$ did not. The impact of PSD on functional outcomes has been extensively studied in various settings. However, it is important to note, given the relative large number of publications available on PSD, that the attention of Nigerian physical therapy research has not been obviously drawn to the potential impact of PSD on function recovery. Elucidating the influence of PSD on function recovery could inform clinical decision-making and help improve prognosis in this vulnerable population of stroke survivors (18).

\section{MATERIALS AND METHODS}

A purposive sample of sixty-six stroke survivors participated in this cross-sectional survey. Ethical approval was obtained from the Health Research and Ethics Committee of the University of Nigeria Teaching Hospital (UNTH), Enugu. Participants were recruited based on the following inclusion criteria: being medically and mentally stable and attending outpatient physiotherapy clinic. Participants who were pregnant or on antidepressant were excluded. The procedure for data collection involved explaining the aims of the research to each participant after which the consent for participation was sought and obtained. Sociodemographic characteristics such as age, sex and duration of stroke were assessed and obtained.

Post-stroke depression was assessed with the Hamilton Depression Rating Scale (HAM-D) (19). It is a 21 items questionnaire: its scoring is based on the first 17. Nine items (items 1, 2, 3, 7, 8, 9, $10,11,15)$ are scored on a 5 -point scale, ranging

DOI: http://dx.doi.org/10.4314/ejhs.v29i1.5 
from $0=$ not present to $4=$ severe. Seven (items 4 , $5,6,12,13,14,17$ are scored from 0 to 2 while the $16^{\text {th }}$ item is scored from 0 to 3 . The minimum score is 0 while the maximum score is 50 . Score $0-7=$ normal, $8-13=$ mild depression, $14-18=$ moderate depression, $19-22=$ severe depression $\geq 23=$ very severe depression. The reliability coefficient range of HAM-D was 0.83-0.99 (20). Sensitivity and specificity were reported to be $86.4 \%$ and $92.2 \%$ respectively (21). The Hamilton Depression rating scale has been validated in Nigerian populations $(22,23)$ and used in several Nigerian studies $(24,25,26)$. The instructions used for assessments are similarly contained in the work of Obembe et al. (26).

The instrument used for the assessment of ADL was the Berthel Index (BI). It contains a total of 10 items describing different activities. The scoring is done by adding individual item scores to give a total score ranging from 0 (totally dependent) to 100 (completely independent). On the BI, lower score indicates greater dependency with ADL. Scores are interpreted as thus: $80-100$ -independent, 60-79 -needs minimal help with ADL, 40-59 -partially dependent, 20-39 -very dependent, and $<20$-totally dependent (27). The BI has good internal consistency with a Cronbach's alpha coefficient of 0.98 ; intra-rater and inter-rater reliabilities are high, with a Pearson's $r$ score ranging from 0.89 to 0.99 (28). The Berthel Index has been validated among stroke survivors in Nigeria (29) and used in several Nigerian studies to evaluate functional independence in activities of daily living $(30,31,32)$. The interview guide used in this study was similar to that of Badaru et al. (32).

Descriptive statistic of frequency, mean and standard deviation were used to summarize the data. Chi-square was used to test for association between functional independence in $\mathrm{ADL}$ and depressions. Unpaired $t$-test was used to compare the mean scores of level of functional independence (ADL) between participants with and without depression. Multivariate analysis was conducted to control for variation in age and duration of stroke among participants. Data was analyzed using SPSS version 23, with $\alpha$ set at 0.05 .

\section{RESULTS}

The mean age of the participants was $57.52 \pm 11.35$ years; more than half $(53.1 \%)$ of them were below 60 years of age. Moving from 30 years to 69 years, the number of stroke survivors gradually increased (from 7 to 11 to 17 to 25 ) until age 70 where it suddenly dropped (to 6). None of the participants was below 30 years. The occurrence of stroke was approximately 1.6 times higher in females than in males. Participants who had stroke for more than 20 months were of a lower proportion $(45.5 \%)$ than those $(54.6 \%)$ who had stroke for $\leq 20$ months (Table 1).

Table 1: Demographic characteristics and duration of stroke survivors.

\begin{tabular}{llll}
\hline Variable & Frequency & Percent & Mean \pm SD \\
\hline Age (years) & & & \\
$30-39$ & 7 & 10.6 & $57.52 \pm 11.35$ \\
$40-49$ & 11 & 16.7 & \\
$50-59$ & 17 & 25.8 & \\
$60-69$ & 25 & 37.9 & \\
$70+$ & 6 & 9.1 & \\
Duration of & & & \\
Stroke (years) & & & \\
$\leq 0.5$ & 9 & 13.6 & $1.75 \pm 1.08$ \\
$0.5-1$ & 14 & 21.2 & \\
$1-2$ & 21 & 31.8 & \\
$>2$ & 22 & 33.3 & \\
Sex & & & \\
Female & 42 & 63.6 & \\
Male & 24 & 36 & \\
\hline
\end{tabular}

Table 2: Association between functional independence in ADL and each of PSD, age, stroke duration and sex.

\begin{tabular}{|l|l|l|}
\hline \multirow{2}{*}{ Variable } & \multicolumn{2}{|l|}{ Functional Independence in ADL } \\
\cline { 2 - 3 } & $\mathbf{X}^{2}$-value & p-value \\
\hline $\begin{array}{l}\text { Post-stroke } \\
\text { depression }\end{array}$ & 72.653 & $0.000^{*}$ \\
\hline Age & 41.817 & $0.000^{*}$ \\
\hline Stroke Duration & 24.525 & $0.017^{*}$ \\
\hline Male sex & 6.299 & 0.178 \\
\hline
\end{tabular}

*significant at $\alpha=0.01 ; \uparrow$ : reference sex; $\mathrm{X}^{2=}$ Chi-square

DOI: http://dx.doi.org/10.4314/ejhs.v29i1.5 


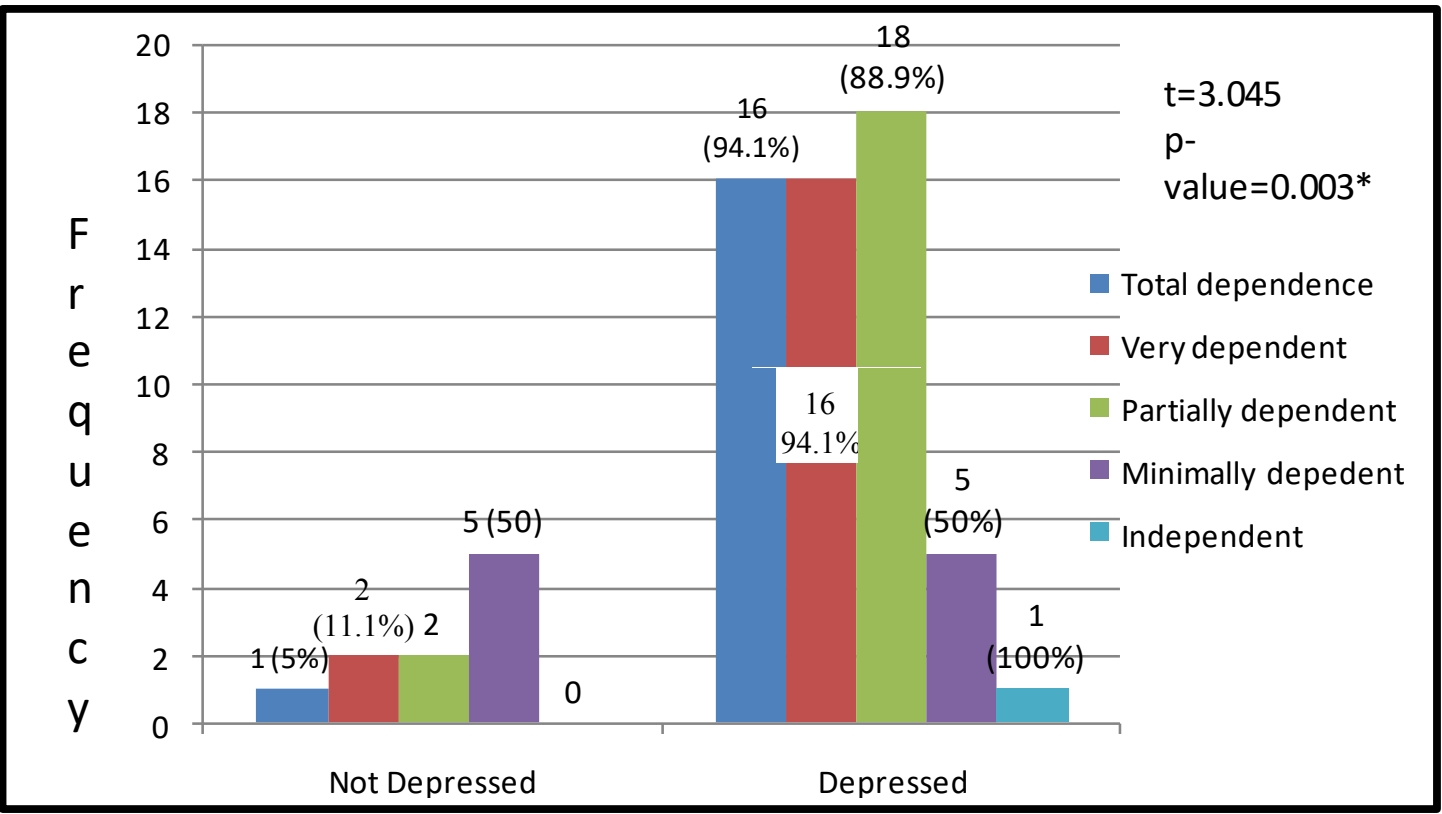

*significant at $\alpha=0.01 ; \mathrm{t}=$ independent $\mathrm{t}$-test

Figure 1: Distribution of Participants and Independent t-test showing Influence of Depression on Functional Independence in $A D L$

Post-stroke depression was associated with poor level of functional independence in ADL $(p=0.000)$. Other factors such as duration of stroke and age were also associated with functional recovery in ADL ( $p=$ 0.000 and 0.017 respectively) (Table 2). The result shows that there were no significant changes in outcome as regards the influence of depression on functional independence in ADL before and after controlling for confounders. An initial odd ratio and $95 \%$ confidence interval of 0.08 (0.017-0.367), $P=$ 0.01 proceeded towards a similar value of 0.05 (0.005-0.510), $P=0.011$ (Figure 1).

\section{DISCUSSION}

In this study, post-stroke depression was associated with functional independence in ADL, and difference in functional independence existed between stroke survivors with and without depression. This observation is similar to those of previous studies by Badaru et al. (32), Lai et al. (33) and Nannetti et al. (34). Previous studies $(35,36)$ have attributed this observation to factors such as low quality of life, probably emanating from several causes such as forgetfulness, feelings of hopelessness, helplessness, anxiety and dehumanization $(35,36)$ subsequent to stroke. Although this study did not evaluate these factors, stroke survivors who lacked social support of their spouse, caregiver(s) and expedient finance may suffer from hopelessness, helplessness, and anxiety (33). The finding that post-stroke depression was associated with functional independence in ADL validates previous reports which suggested that poststroke depression has a negative impact on functional recovery process after discharge (34). It also suggests that post-stroke depression could independently predict functional independence of stroke survivors at discharge (33). Similarly, Lai et al. (33) reported that stroke survivors with depression stood higher chance of achieving less independence in ADL and some instrumental activities of daily living when compare to those without depression.

Furthermore, the result of the association between PSD and functional recovery is in line with (35), in which clinically important differences were found in levels of depression between those with lower functional independence and those more independent in ADL after stroke. This suggests that attention should be paid to addressing PSD in stroke patients in order to help them recover as much

DOI: http://dx.doi.org/10.4314/ejhs.v29i1.5 
functional independence as possible (35). Initial physical therapy examination should include assessment for post-stroke depression as this might be help therapists in making informed clinical decision such as referring patients for expert management by clinical psychologist or psychiatrist, or rendering some informal psychotherapy.

The fact that participants' age and duration of stroke were not standardized constituted a limitation to this study. This is expected to influence the individual patient's level of post-stroke depression and ADL. This limitation was, however, addressed by controlling for duration of stroke and age and their effects on ADL functional recovery. Afterwards, interestingly, the outcome of effect remained the same. Owing to the use of cross-sectional survey design in this study, it was not feasible to assess poststroke depression and the degree of change in depression score with time. Also, the inability to conduct retrospective assessment of stroke severity test constitutes a limitation to this study. The study was limited not to make an inference of causality since the extent of recovery of individual participant from onset of stroke to time of participation in the study could not be assessed. In conclusion, poststroke depression was associated with less functional independence in ADL. A longitudinal study, with a larger sample size, evaluating impacts of post-stroke depression and treatments of depression on ADL is, however, recommended so as to improve external validity and relevance to clinical practice.

\section{ACKNOWLEDGEMENTS}

We hereby express our gratitude to Dr Israel Akunne, and head of Physiotherapy department Enugu State University Teaching Hospital, Mr Agwagu Ikechukwu for their moral support during the study.

\section{REFERENCES}

1. Adamson J., Beswick A., Ebrahim S. Stroke and disability. J. Stroke Cerebrovasc. Dis 2004; 13: 171.

2. Owolabi MO, Arulogun O, Melikam S, Adeoye AM, Akarolo-Anthony S. Akinyemi R et al. The burden of stroke in Africa: a glance at the present and a glimpse into the future. Cardiovasc $J$ Afr 2015; 26: S27-S3.

3. American Heart Association. Heart and Stroke Statistical Update. American Heart Association, Dallas, Texas 2002.
4. Rosamond W, Flegal K, Furie K, Go A, Greenlund $\mathrm{K}$, Haase $\mathrm{N}$ et al. Heart disease and stroke statistics--2008 update: a report from the American Heart Association Statistics Committee and Stroke Statistics Subcommittee. Circulation 2008; 117: e25-146.

5. Asakawa T, Zong L, Wang L, Xia Y, Namba H. 2017. The Unmet Challenges for Rehabilitation after Stroke in China. Lancet 2017; 390: 121-122.

6. Kong KH, Loh YJ,Thia E, Chaiand A, Ng YC. Relationship between post-stroke depression and upper limb recovery in patients admitted to a Rehabilitation Unit. Journal of Physical Medicine and Rehabilitation 2017; 1:1.

7. Robinson RG and Jorge RE. Post-stroke depression: A review. American Journal of Psychiatry 2016; 173: 221-231.

8. Carson A, MacHale S, Allen K, Lawrie SM, Dennis M, House A, Sharpe M. Depression after Stroke and lesion location: a systematic review. Lancet 2000; 356:122-126.

9. Vataja R, Pohjasvaara T, Leppavuori A, Mantyla $R$, Aronen HJ, Salonen $O$ et al. Magnetic resonance imaging correlates of depression after ischemic stroke. Arch Gen Psychiatry 2001; 58: 925-931.

10. Hasan SM, Rancourt SN, Austin MW and Ploughman M. Defining Optimal MProbic Exercise Parameters to Affect Complex Motor and Cognitive Outcomes after Stroke: A Systematic Review and Synthesis. Neural Plasticity 2016; 2016: 2961573.

11. Gillen R, Tennen H, Mckee TE, Gernert-Dott P and Affleck G. Depressive symptoms and history of depression predict rehabilitation efficiency in stroke patients. Archives of Physical Medicine and Rehabilitation 2001; 82: 1645-1649.

12. Hackett ML, Pickles K. Part I: frequency of depression after stroke: an updated systematic review and meta-analysis of observational studies. Int J Stroke 2014; 9: 1017-10.

13. Gainottia G, Antonuccib G, Marraa C, Paoluccic S. 2001. Relationship between depression after stroke, antidepressant therapy, and functional recovery. Neurology, Neurosurgery and Psychiatry 2001; 71: 2.

14. Hermann N, Black SE, Lawrence J, et al. Szekely C, Szalai JP. 1998. The Sunnybrook stroke study. A prospective study of depressive symptoms and functional outcome. Stroke 1998; 29: 618-624.

15. Parikh RM, Robinson RG, Lipsey JR, Starkstein SE, Fedoroff JP and Price T 1990. The impact of post stroke depression on recovery in activities of

DOI: http://dx.doi.org/10.4314/ejhs.v29i1.5 
daily living over a 2-year follow-up. Arch Neurol 1990. 47: 785.

16. Loong CK, Kenneth NKC, Paulin ST. Post-stroke depression: outcome following rehabilitation. Aust N Z J Psychiatry 1995; 29: 609-614.

17. Paolucci S, Antonucci G, Pratesi L, Traballesi M, Grasso MG, Lubich S. Post-stroke depression and its role in rehabilitation of inpatients. Arch Phys Med Rehabil 1999; 80: 985-990.

18. Kwakkel G, Kollen BJ, Krebs HI. Effects of robotassisted therapy on upper limb recovery after stroke: a systematic review. Neurorehabil Neural Repair 2008. 22: 111.

19. Hamilton, M. A Rating Scale for Depression. Journal of Neurology, Neurosurgery, and Psychiatry 1960; 23: 56-62.

20. Istriana E, Kurnia E, MaSci AW, Hidayat T, Pinxten L, Arnt Schellekens CA. 2013. Excellent reliability of the Hamilton Depression Rating Scale (HDRS-21) in Indonesia after training. Asia Pac Psychiatry 2013; 5: 141-6.

21. Strik JJ, Honig A, Lousberg R, Denollet J: Sensitivity and specificity of observer and selfreport questionnaires in major and minor depression following myocardial infarction. Psychosomatics 2001; 42: 423-428.

22. Okulate GT, Jones OB. Two depression rating instruments in Nigerian patients. Niger Postgrad Med J 2002; 9: 74-78.

23. Agbir TM, Audu MD, Adebowale TO, Goar SG. Depression among medical outpatients with diabetes: a cross sectional study at Jos University Teaching Hospital, Jos, Nigeria. Ann African Med 2010; 9:5-10.

24. Ali MA, Onyencho VC, Adebowale OT. Demographic and Clinical factors on Depression among Stroke Patients. American Journal of Clinical Medicine Research 2016; 4:38-42.

25. Abubakar SA, Obiakor RO, Sabir AA, Iwuozuo EU, Magaji MI. Depression in long-term stroke survivors. Sub-Saharan African Journal of Medicine 2014; 1: 119-123.

26. Obembe A, Mapayi B, Johnson O, Agunbiade T, Emechete A. 2013. Community reintegration in stroke survivors: Relationship with motor function and Depression. Hong Kong Physiotherapy Journal; 31:69-74.

27. Shinar D, Gross CR, Bronstein KS, Licata-Gehr EE, Eden DT, Cabrera AR et al. "Reliability of the activities of daily livings Scale and its use in telephone interview," Archives of Physical Medicine and Rehabilitation 1987; 68: 723-728.

28. Gladman JRF, Lincoln NB, and Adams SAA. "Use of the extended ADL scale with stroke patients". Age and Ageing 1993; 22: 419-424, 1993.

29. Obembe AO, Onigbinde AT, Fajinmi PO. Reliability and Concurrent Validity of Modified Barthel Index in a Nigerian Language. Journal of the Nigeria Society of Physiotherapy 2012; 20: 21.

30. Aliyu S, Ibrahim A, Saidu H, Owolabi LF. Determinants of health-related quality of life related quality of life in Kano, Northwest Nigeria. American Journal of Clinical Medicine Research; 4: $38-42$.

31. Hamza AM, Al-Sadat N, Siew Yim Loh SY, and Nowrozy NK. Predictors of Poststroke Health-Related Quality of Life in Nigerian Stroke Survivors: A 1-Year Follow-Up Study. BioMed Research International 2014; http://dx.doi.org/10.1155/2014/350281.

32. Badaru UM, Ogwumike OO, Adeniyi AF, and Olowe OO. Variation in Functional Independence among Stroke Survivors Having Fatigue and Depression. Neurol Res Int 2013; 2013: 842980.

33. Lai S, Duncan PW, Keighley J, Johnson D. Depressive symptoms and independence in BADL and IADL. Journal of Rehabilitation Research and Development 2002; 39: 589-596.

34. Nannetti L, Paci M, Pasquini J, Lombardi B, Taiti PG. 2005. Motor and functional recovery in patients with post-stroke depression. Disability and Rehabilitation 2005; 27: 170-175.

35. Raju RS, Sarma PS, Pandian JD. 2010. Psychosocial problems, quality of life, and functional independence among Indian stroke survivors. Stroke 2010; 41: 2932-2937.

36. Brown C, Hasson H, Thyselius V, Almborg A-H. 2012. Post-stroke depression and functional independence: a conundrum. Acta Neurologica Scandinavica 2012; 126: 45-51.

DOI: http://dx.doi.org/10.4314/ejhs.v29i1.5 